\title{
Selective stimulation of the spinal cord surface using a stretchable microelectrode array
}

\author{
Kathleen Williams Meacham ${ }^{1}$, Liang Guo ${ }^{1}$, Stephen P. DeWeerth' ${ }^{1}$ and Shawn Hochman 1,2* \\ ${ }^{1}$ The Laboratory for Neuroengineering, Wallace H. Coulter Department of Biomedical Engineering, Georgia Institute of Technology, Atlanta, GA, USA \\ 2 Department of Physiology, Emory University School of Medicine, Atlanta, GA, USA
}

Edited by:

Mario I. Romero-Ortega, University of Texas Southwestern Medical Center, USA

\section{Reviewed by:}

Xavier Navarro, Universitat Autonoma de Barcelona, Spain

Jeffrey Petruska, University of

Louisville, USA

${ }^{*}$ Correspondence:

Shawn Hochman, Department of Physiology, Emory University School of Medicine, 615 Michael Street, Atlanta, GA 30322, USA.

e-mail:shochman@physio.emory.edu
By electrically stimulating the spinal cord, it is possible to activate functional populations of neurons that modulate motor and sensory function. One method for accessing these neurons is via their associated axons, which project as functionally segregated longitudinal columns of white-matter funiculi (i.e., spinal tracts). To stimulate spinal tracts without penetrating the cord, we have recently developed technology that enables close-proximity, multi-electrode contact with the spinal cord surface. Our stretchable microelectrode arrays (sMEAs) are fabricated using an elastomer polydimethylsiloxane substrate and can be wrapped circumferentially around the spinal cord to optimize electrode contact. Here, sMEAs were used to stimulate the surfaces of rat spinal cords maintained in vitro, and their ability to selectively activate axonal surface tracts was compared to rigid bipolar tungsten microelectrodes pressed firmly onto the cord surface. Along dorsal column tracts, the axonal response to sMEA stimulation was compared to that evoked by rigid microelectrodes through measurement of their evoked axonal compound action potentials (CAPs). Paired $t$-tests failed to reveal significant differences between the SMEA's and the rigid microelectrode's stimulus resolution, or in their ranges of evoked CAP conduction velocities. Additionally, dual-site stimulation using sMEA electrodes recruited spatially distinct populations of spinal axons. Site-specific stimulation of the ventrolateral funiculus - a tract capable of evoking locomotor-like activity - recruited ventral root efferent activity that spanned several spinal segments. These findings indicate that the sMEA stimulates the spinal cord surface with selectivity similar to that of rigid microelectrodes, while possessing potential advantages concerning circumferential contact and mechanical compatibility with the cord surface.

Keywords: multielectrode array, neuroprosthesis, brain computer interface, neurophysiology, spinal cord injury, PDMS, neurorehabilitation, spinal cord

\section{INTRODUCTION}

Recovery of motor function lost to disease or injury is an objective shared by approximately 255,000 individuals in the United States living with spinal cord injury (NSCISC, 2008). This goal is also shared by 1.5 million Americans living with motor-control impairing neurological disorders (National Institute of Neurological Disorders and Stroke, 2009) as well as the five million individuals experiencing temporary or permanent loss of function due to stroke (Rosamond et al., 2008). For over 40 years, electrical stimulation technologies have been developed to elicit and control motor activity such as upper and lower extremity movement, bladder and bowel control, and respiratory pacing (Peckham and Knutson, 2005). Most of these devices activate each muscle or peripheral nerve separately, and are referred to as functional electrical stimulation (FES) devices.

A trade-off that traditional FES devices make for their direct muscle and peripheral nerve access is that their interfaces bypass the upstream spinal circuitry that naturally creates adaptable, multiple-muscle movements (Mushahwar and Horch, 1997). Importantly, experiments in spinal cord transected cats and rats have shown that the spinal neurons that coordinate motor behaviors such as locomotion remain intact following disconnection from descending command (Guertin and Steuer, 2009) and are accessible via surface stimulation (Gerasimenko et al., 2008; Courtine et al., 2009). Spinal cord epidural stimulation (ES) approaches to reactivate movement have utilized some of this remaining spinal circuitry to evoke coordinated movements similar to volitional gait (Courtine et al., 2009). In ES for evoking lower limb movement, electrodes are typically placed near the dorsal column, and are thought to activate low threshold, dorsal root (sensory) afferents as well as spinal neurons in the dorsolateral funiculus (DLF; Gerasimenko et al., 2008). Spinal neurons can also be activated via intraspinal microstimulation (ISMS), which involves insertion of stimulating microwires into gray matter laminae of the lumbosacral enlargement. This method has been used to recruit hindlimb activity in a selective, graded, and controllable manner (Tresch and Bizzi, 1999; Saigal et al., 2004). ISMS of the spinal cord has been shown to directly and indirectly activate motoneurons via intraspinal axons (Tresch and Bizzi, 1999) as well as the axons of sensory afferents whose collaterals extend many spinal segments (Gaunt et al., 2006). 
For both epidural and intraspinal stimulation, the axons of neurons are activated at lower thresholds than their associated cell bodies (Ranck, 1975; Gustafsson and Jankowska, 1976; Gaunt et al., 2006). Conveniently, the axons of most spinal neurons have collaterals located in longitudinal white matter tracts surrounding the central gray matter (i.e., spinal tracts), and have topographic relationships to distinct functional regions in gray matter laminae (Hochman, 2007). Direct contact and stimulation of these spinal tracts, therefore, has the potential to recruit functional subpopulations of spinal neurons. The ability of spinal cord surface stimulation to elicit coordinated motor neuron activity patterns, including fictive locomotion, has been demonstrated in the in vitro isolated spinal cords of neonatal rats (Iwahara et al., 1991; Magnuson and Trinder, 1997; Todd et al., 2009). In these studies, glass or metal electrodes were pressed directly onto the spinal cord surface at either the lower-thoracic ventrolateral funiculus (VLF; Magnuson and Trinder, 1997; Antonino-Green et al., 2002), the lumbosacral enlargement's dorsal column (Iwahara et al., 1991), the lumbosacral enlargement's ventral funiculus (Iwahara et al., 1991), or the sacral spinal dorsal column (Todd et al., 2009).

Regionally precise stimulation of these and other spinal cord surface locations has the potential to enable a more controlled study and regulation of evoked neural activity. Selective surface stimulation can be facilitated by electrodes placed in very close contact to the interfaced neural tissue (Rutten, 2002; Rodgers et al., 2007). In addition, high spatial resolution MEAs have been shown to facilitate stimulus patterns that use spatiotemporal adaptation as well as fatigue-minimizing interleaving (McDonnall et al., 2004).

Safety constraints must be determined and followed when placing close-proximity, high-resolution MEAs on neural tissue; for example, the charge/phase and charge density should be below pre-determined thresholds found to be harmful to the interfaced biology (Merrill et al., 2005). Additionally, mechanical damage by either the electrodes or their substrate must be minimized. As the nervous system is comprised of soft tissue, arrays of rigid microelectrodes have the potential to produce significant mechanical damage. Tissue/electrode property mismatches - including differences in mechanical compliance, damping, and density - are a particularly significant issue for long-term implantable devices. Consequences range from reduced interface integrity to irreversible loss of neuronal function due to scarring. Such damage has been evaluated and quantified for several types of MEAs (Biran et al., 2005; Leventhal et al., 2006; McConnell et al., 2009), and techniques for its reduction or prevention continue to be explored (Grill et al., 2009).

With the above-mentioned constraints in mind, we have developed an elastomer-substrate MEA technology for conformal contact with the spinal cord surface (Guo et al., 2007; Meacham et al., 2008; Guo and DeWeerth, 2009b; Figure 1A). This stretchable MEA (sMEA) is comprised of gold traces and electrodes that are photo-patterned between layers of thin-film polydimethylsiloxane (PDMS). PDMS is a gas-permeable elastomer with well-characterized biocompatibility (Belanger and Marois, 2001; Peterson et al., 2005; Guven et al., 2006) and expanding use as a microfluidic and cell-interfacing substrate. In addition, its elasticity is orders of magnitude greater than more traditional flexible electrode array materials, including parylene and polyimide (Yang et al., 1998; Armani et al., 1999; Rousche et al., 2001; Table 1). To further isolate the space between electrode and interfaced tissue, each electrode is surrounded by a raised, conical isolation well (Figure 1B; Guo et al., 2010). The impedance profiles of these electrodes compare favorably to those of rigid microelectrodes used for stimulation and recording of neurons (Guo et al., 2010), and iterations of this design have been shown to maintain electrical connectivity during both stretching (Meacham et al., 2008) and bending (Guo and DeWeerth, 2010).

In the following experiments, we hypothesize that the sMEA can stimulate spinal cord surface tracts with axonal selectivity that is the same as that evoked by a rigid, bipolar microelectrode pressed

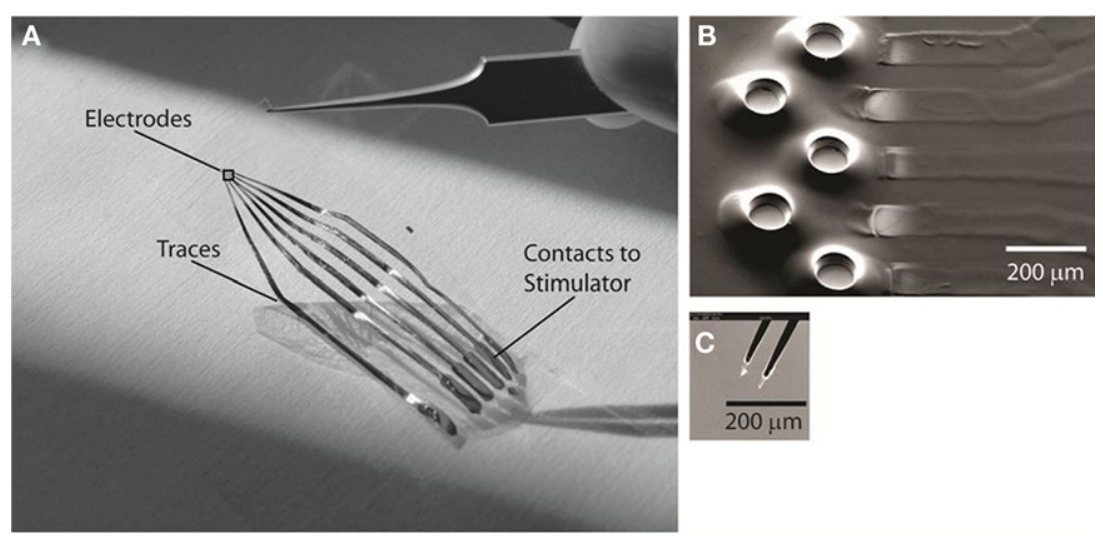

FIGURE 1 |The polydimethyl siloxane (PDMS)-substrate MEA with conical isolation wells. The configuration used for these experiments has five electrodes. (A) Photograph of the stretchable MEA (sMEA), indicating the location of cord-interfacing electrodes, traces, and contacts to external stimulating hardware. The black square over the electrodes indicates the approximate region for (B). (B). Scanning electron micrograph of the exposed gold stimulating electrodes. The raised PDMS wells surrounding each electrode were designed to further isolate the space between a given electrode and its interfaced soft tissue surface. (C) Scanning electron micrograph of the tungsten rigid microelectrode (Harvard Apparatus, Inc.), bipolar configuration, used as control comparison for selective stimulation of the spinal cord surface. 
Table 1 | Comparison of Young's Moduli for MEA (multi-electrode array) substrates and spinal cord.

\begin{tabular}{ll}
\hline Material & Young's modulus (stiffness) \\
\hline Parylene & 4-4.5 GPa (Yang et al., 1998) \\
Polyimide & 2.3-2.8 GPa (Rousche et al., 2001) \\
PDMS & $0.05-1.79 \mathrm{MPa}$ (Armani et al., 1999; Brown et al., 2005) \\
Spinal Cord & $0.1-1.4 \mathrm{MPa}$ (Mazuchowski and Thibault, 2003) \\
\hline
\end{tabular}

directly onto the cord. To test our hypothesis, we wrap sMEAs around isolated young rat spinal cords maintained in vitro, with electrodes overlying the dorsal surface for bipolar stimulation. Stimulus selectivity is quantified by measuring the orthogonal (lateral) spread of activated white matter tracts, as represented by evoked tract compound action potentials (CAPs).

Rigid microelectrodes pressed firmly upon - but not penetrating - the cord are used as a comparison because of their well-established use in experimental neurophysiology protocols requiring selective surface stimulation (Loeb et al., 1995). We also compare sMEA vs. rigid microelectrode's ability to recruit axons of increasingly slower conduction velocities as a function of electrode proximity and stimulus magnitude.

We then evaluate the ability of dual-site sMEA stimulation to activate distinct axonal tracts, and the ability of single-pulse sMEA stimulation to evoke motoneuron activity in ventral roots associated with hindlimb flexor and extensor movements (Kiehn and Kjaerulff, 1996).

\section{MATERIALS AND METHODS}

The spinal cords of 20 Sprague-Dawley young rats (postnatal days 10-14) were isolated and maintained in vitro for sMEA and rigid electrode interfacing and evaluation. All animal procedures were performed in accordance with policies of the Association for the Assessment and Accreditation of Laboratory Animal Care International and approved by Emory University's Institutional Animal Care and Use Committee. Each rat was administered 10\% wt./vol. urethane $(2.0 \mathrm{mg} / \mathrm{kg}$ injected intraperitoneally) and, following confirmation of anesthesia, submerged in an ice slurry for $5 \mathrm{~min}$ to decrease body temperature. Following subsequent decapitation and evisceration, the cervical-to-sacral spinal cord was isolated along with ventral and dorsal roots and placed in an oxygenated $\left(95 \% \mathrm{O}_{2}, 5 \% \mathrm{CO}_{2}\right)$ bath of artificial cerebrospinal fluid (aCSF, in mM: $\mathrm{NaCl} 128 ; \mathrm{KCl} 1.9 ;$ D-glucose $10 ; \mathrm{MgSO}_{4} 1.3$; $\mathrm{CaCl}_{2} 2.4 ; \mathrm{KH}_{2} \mathrm{PO}_{4} 1.2$; and $\mathrm{NaHCO}_{3}$ 26). Further isolation, data collection, and analysis procedures were specific to experiments and are described in the following sections.

\section{PREPARATION FOR MEA-SPINAL CORD INTERFACING}

The fabrication steps for the conical-well sMEA technology have been reported previously (Guo et al., 2010). Briefly, our fabrication process involves lift-off patterning of gold features onto a PDMS substrate cured on a glass slide, lithographically defining sacrificial posts where electrode and contact pad openings are to be made in assisting the formation of conical wells, covering the sample with another thinner PDMS layer for encapsulation, and then removing the sacrificial posts to expose the electrodes and contact pads.

The sMEA substrate thickness is approximately $80 \mu \mathrm{m}$, with the isolation wells surrounding each electrode possessing an additional height of $40 \mu \mathrm{m}$. The exposed electrode surfaces are each approximately $100 \mu \mathrm{m}$ in diameter, and minimum inter-electrode spacing (between electrodes in the same row) is $230 \mu \mathrm{m}$ (Guo et al., 2010; Figure 1). Fabrication, measurement, and imaging of the sMEAs were undertaken using the Microelectronics Research Center core facility at Georgia Institute of Technology. A five-electrode configuration was chosen for these experiments; in related work, eight-electrode version of the sMEA with integrated packaging has also been implemented successfully (Guo and DeWeerth, 2009a).

Prior to in vitro testing, each sMEA was treated briefly with oxygen plasma and stored in deionized water for preservation of hydrophilicity (Guo et al., 2010). Contacts on the MEA were adapted to leads for the MCS STG-2008 stimulator (MultiChannel Systems) using 32 AWG wires (Belden, Inc.). These wires were bonded to each contact using conductive epoxy (CircuitWorks CW2400) and sealed with a thin layer of PDMS (Sylgard 184, Dow Corning). PDMS tabs were cut out of the sMEA substrate on either side of the five-electrode exposures prior to interfacing. These tabs facilitated conformal attachment of the sMEA to a single segment of the spinal cord, and enabled a snug, customized fit as the wrapped around tab could be threaded through an ovalcut opening in the opposite side (Figure 2). The sMEA was then wrapped around a spinal thoracic segment with the exposures facing inward.

\section{ELECTROPHYSIOLOGY: WHOLE-CORD EXPERIMENTS}

The first series of experiments assessed the degree to which adjacent axonal tracts were activated by single-site surface stimulation by the sMEA, as compared to that evoked by a rigid tungsten microelectrode placed directly onto the same longitudinal tract (Figure 2). Immediately following isolation, in vitro cords were secured using insect pins $(1.0 \mathrm{~mm}$, Fine Science Tools) in a Sylgard-coated Petri dish containing cold $\left(4^{\circ} \mathrm{C}\right)$, oxygenated aCSF. Dura was carefully and thoroughly removed, and the cord was given an hour to equilibrate at room temperature before further experimentation.

To stimulate the cord, sMEA electrodes were placed directly on the center of the dorsal column at thoracic levels 6,7 , or 8 . For comparison, a conventional tungsten bipolar electrode (conicalshaped exposed tip with base diameter $5 \mu \mathrm{m}$, exposed tip height $25 \mu \mathrm{m}, 50-100 \mu \mathrm{m}$ inter-electrode distance; Harvard Apparatus, Inc.) was pressed firmly onto - but not penetrating - the cord surface immediately caudal to the stimulating sMEA electrode. For all experiments, the tungsten electrode was placed at the same, fixed (approximately 45\%) angle to the spinal cord to ensure consistent amount of electrode contact. To maximize the probability that this rigid control electrode position was activating the same longitudinal tract as the sMEA electrode, both electrode types were positioned to evoke a maximal CAP response on the same caudal tract, as confirmed with a surface recording electrode (Figure 2).

The dorsal column was chosen because its axon composition is well-characterized and because it possesses architecture comprised of mostly parallel tracts (Willis and Coggeshall, 2004). The 

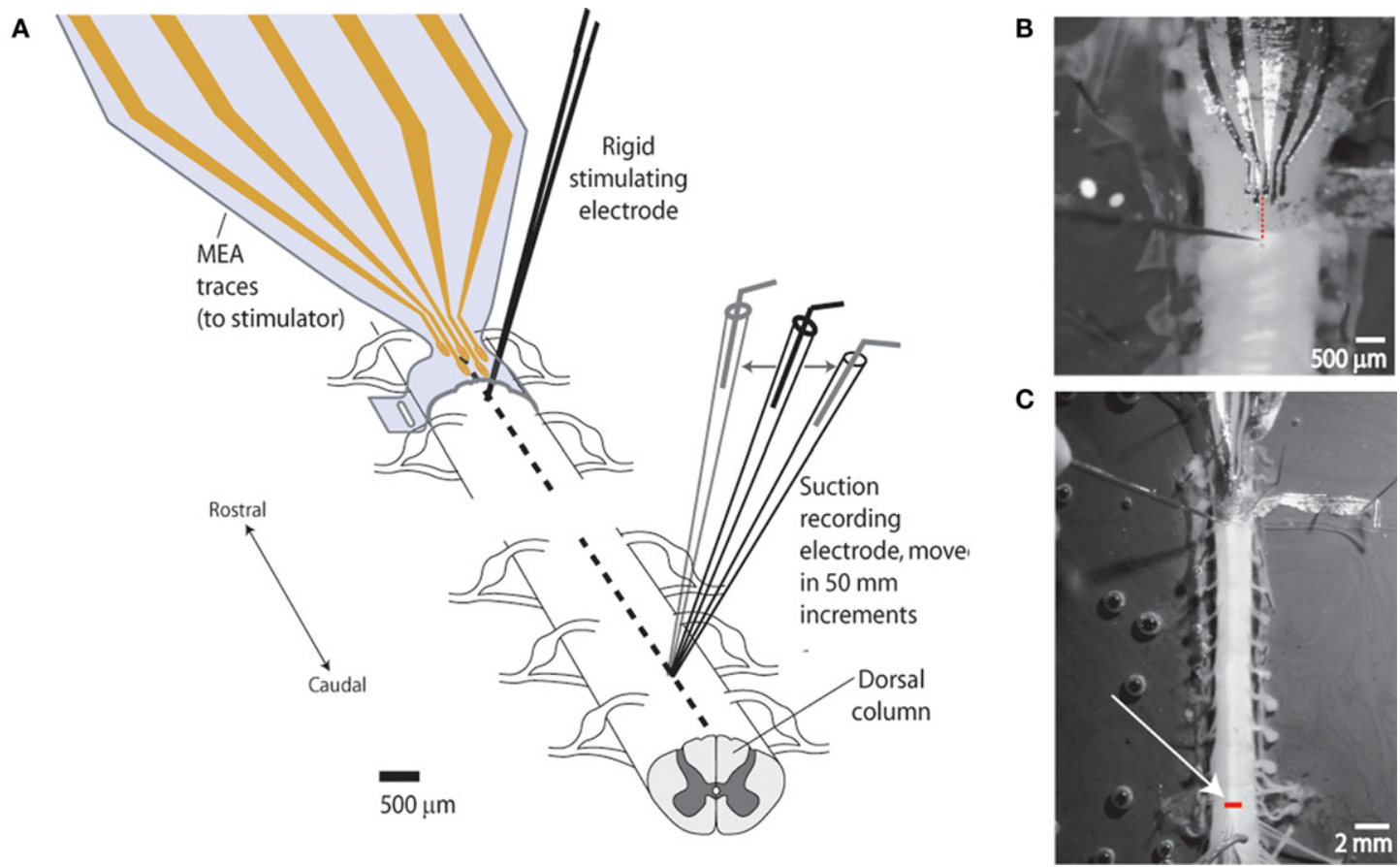

FIGURE 2 | Experimental setup for measuring degree of lateral stimulus spread (spatial selectivity). (A) Schematic of setup. Studies were performed to demonstrate the capacity of the sMEA to activate a specific region of longitudinally oriented axonal bundles (spinal tracts) in the in vitro, isolated spinal cord of postnatal days 10-14 rats. Single-site sMEA stimuli were delivered to the surface of the cord (thoracic levels 6-8) and the evoked compound action potential (CAP) response was recorded on adjacent white matter tracts located $10-15 \mathrm{~mm}$ (approximately eight spinal segments) caudal to the site of activation. A rigid tungsten microelectrode stimulating the same longitudinal tract was used as a comparison. (B) Photograph of sMEA and tungsten electrode positions on cord surface. The sMEA was wrapped, exposures facing inward, around the spinal cord, and delivered bipolar stimuli between the second and third electrodes from the left. Dotted line shows alignment of bipolar stimulus locations for the two electrode types (sMEA and tungsten). (C) Photograph of in vitro setup showing recording location. White arrow points to glass suction recording electrode tip, which was moved in $50 \mu \mathrm{m}$ lateral increments to measure CAPs evoked from the stationary sMEA and rigid tungsten electrodes. Bar on cord shows lateral range of recordings (>700 $\mu \mathrm{m})$. dorsal column is primarily responsible for conveying ascending proprioceptive, fine touch, and vibration information from primary afferents and a class of ascending tract neurons. It also contains $\mathrm{A} \delta$ and unmyelinated $\mathrm{C}$ visceral afferents (Willis et al., 1999). It has been shown that, in the adult rat dorsal column, at least $2 / 3$ of the axons in the dorsal column are myelinated $A \alpha, A \beta$, or propriospinal fibers with diameters of $1-10 \mu \mathrm{m}$, and that the remaining $1 / 3$ of axons are $\mathrm{A} \delta$ or $\mathrm{C} /$ unmyelinated propriospinal fibers with diameters of 0.2-1 $\mu \mathrm{m}$ (Chung and Coggeshall, 1983; Patterson et al., 1989). In the juvenile rat, however, the composition of the dorsal column has a higher ratio of unmyelinated-tomyelinated fibers (Chung and Coggeshall, 1987). To our knowledge, activation threshold in the juvenile rat dorsal column has not been investigated previously. However, the activation thresholds for these afferents within the peripheral nerve have been estimated in rats in this age range in vitro where it has been shown that they are recruited in the order of $A \alpha \beta, A \delta$, and $C$ with constant current stimulation intensities of $50 \mu \mathrm{A} / 50 \mu \mathrm{s}, 500 \mu \mathrm{A} / 50 \mu \mathrm{s}$ $500 \mu \mathrm{A} / 500 \mu \mathrm{s}$, respectively (Thompson et al., 1990). Associated conduction velocities for these afferent fiber groups in peripheral nerve have been reported as 2.4-6.7 (A $\alpha \beta$ fibers), 0.6-4.3 and ( $A \delta$ fibers), and 0.3-0.5 m/s (unmyelinated C fibers; Thompson et al., 1990).
For all white matter tract selectivity studies, the delivered stimuli were single, charge-balanced, $500 \mu$ s duration current pulses using adjacent electrodes $(160 \mu \mathrm{m}$ inter-electrode distance for sMEA, $50-100 \mu \mathrm{m}$ inter-electrode distance for rigid tungsten bipolar electrode). A current (vs. voltage) delivery modality was employed based on evidence that regulated current waveforms guarantee generation of electric fields that are independent of electrode polarization (Guo and DeWeerth, 2009a). A charge-balanced square wave pulse was used to minimize possible charge injection damage to tissue (Merrill et al., 2005). The minimum current value at which a CAP was visible on any distal white matter tract was defined as the threshold stimulus value $(\mathrm{T})$. Amplitude multiples of these threshold values (1.0-2.0T, in $0.2 \mathrm{~T}$ increments) were used to stimulate the cord to evoke increasingly stronger evoked CAPs, and this series of stimuli were repeated as the recording electrode was moved incrementally across the surface of the cord.

To measure activation of axonal tracts, a single glass recording suction electrode $(40-50 \mu \mathrm{m}$ internal diameter; described in more detail below and shown in Figure 2) was used to record evoked CAPs in $50 \mu \mathrm{m}$ lateral increments across the cord surface (MO-10 One-axis Oil Hydraulic Micromanipulator, Narishige International USA). This electrode was placed $10-15 \mathrm{~mm}$ caudal to the stimulation site (typically spinal lumbar level L2) to allow 
for temporal separation of stimulus artifact and the evoked CAP. A reference ground electrode was placed in the bath at the caudal end of the spinal cord. For a subset of these experiments, an additional, adjacent pair of sMEA electrodes was also used to stimulate the cord. This was done to determine the resolution of white matter tract selectivity achievable between adjacent sMEA electrodes (bipolar configuration).

\section{ELECTROPHYSIOLOGY: HEMISECTED SPINAL CORD}

For the second series of experiments, which evaluated motoneuron responses to sMEA surface stimulation, cord hemisections were performed to ensure sufficient surface area exposure for complete oxygenation of all spinal gray matter. Mid-sagittal hemisection was accomplished using $0.10 \mathrm{~mm}$ diameter insect pins (light brushing of the cord with the sharp end) and was performed immediately after isolation and placement of the cord into a bath of ice-cold, oxygenated, high sucrose-containing aCSF (in mM: sucrose 250; $\mathrm{KCl}$ 2.5; $\mathrm{NaHCO}_{3} 26 ; \mathrm{NaH}_{2} \mathrm{PO}_{4}$ 1.25; D-glucose 25; $\mathrm{MgCl}_{2} 3$; $\mathrm{CaCl}_{2}$ 1). Following hemisection, the spinal cord was placed in room temperature, oxygenated aCSF and allowed to equilibrate for at least $1 \mathrm{~h}$ before commencement of sMEA testing. Throughout the experiments that followed, the viability of spinal neurons was monitored intermittently by evaluating the magnitude of the reflex at the spinal cord lumbar level 5 (L5) ventral root evoked by stimulation of dorsal root L5.

Following equilibration of the hemisected cord, the sMEA was wrapped around the cord's lateral surface, and its electrodes (bipolar configuration) were used to stimulate the surface of 12th thoracic segment along the DLF, lateral funiculus (LF), and VLF. These spinal tract regions contain a combination of ascending, descending, and propriospinal axonal tracts of importance to movement coordination as well as sensory transmission (Davidoff, 1983; Loy et al., 2002; Noga et al., 2003). Single, monophasic current pulses were applied at each of three electrode pair sites, using minimum current values required to elicit a visible evoked response on either the recorded ventral roots or on that tract's recorded surface CAP. For recording, glass suction electrodes were placed on the ventral root at lumbar level 2 (L2), the ventral root at lumbar level 5 (L5), as well as on the surface of the spinal cord at the 6th lumbar level DLF and VLF. Previous work has shown that recordings from ventral roots L2 and L5 are predominantly associated with hindlimb flexor (L2) and extensor (L5) motor output, respectively (Kiehn and Kjaerulff, 1996). Ventral root recording was accomplished using bipolar glass suction electrodes $(90-150 \mu \mathrm{m}$ internal diameter glass, silver chlorided wire differential recording); surface recording electrodes had smaller internal diameter (40-50 $\mu \mathrm{m})$.

\section{DATA COLLECTION AND ANALYSIS}

All extracellular responses were amplified by 10,000 and recorded using pClamp data acquisition software (Axon Instruments, now part of MDS Analytical Technologies). For a given stimulus amplitude and electrode type, 7-10 trials of spinal cord responses were recorded. The strength of the evoked responses for both CAPs and ventral root responses was quantified via MATLAB routines that rectified and integrated the signal for the time window of $100 \mathrm{~ms}$ post-stimulus, starting immediately after the end of a given stimulus artifact. To adjust for baseline noise, a 100-ms window of rectified, integrated pre-stimulus recording was subtracted from each value.

For selectivity comparisons across animals, values were also amplitude-normalized such that the maximal response was equal to 1 . Visual verifications of response onset and offset values were performed for each trial used in analysis, and the consistency of response across trials was also verified visually. The time to onset and duration of a given response was calculated using a MATLAB detection algorithm, which used a combination of threshold detection and time windowing to identify the onset and offset of a given response. Values for delay and duration of evoked response were subsequently used, in combination with distance measurements, to calculate axonal fiber conduction velocities. When appropriate, paired Student's $t$-tests with two-tailed distribution were used to statistically compare spinal cord responses to each of the electrode methodologies.

\section{RESULTS}

In the evaluation of in vitro stimulation efficacy of the sMEA, five different characteristics were assessed: charge density required for threshold activation of CAPs, spatial selectivity, axonal conduction-velocity selectivity, dual-site stimulus precision, and ability to recruit motoneurons. Spatial selectivity was defined as the ability of single-site stimulation to activate axons with a highly localized pattern comparable to conventional rigid stimulating electrodes.

Axonal conduction-velocity selectivity was defined as the sMEA's ability to stimulate axonal fibers of incrementally lower conduction velocities as a function of stimulating electrode proximity and current amplitude. Dual-site stimulus precision was defined as the degree to which adjacent electrodes could discriminate between activation of parallel tracts of axons. Ability to recruit motoneurons was defined as the sMEA's ability to evoke motor output via surface spinal tract stimulation, as measured by ventral root responses associated with hindlimb flexor and extensor activity (Kiehn and Kjaerulff, 1996). The following sections describe the results of these analyses, and demonstrate that the sMEA can be used to stimulate spinal tracts in a precise and controllable manner.

\section{CHARGE AND CURRENT DENSITY COMPARISON}

The minimum current required to evoke a detectable CAP on a recording electrode placed on the same longitudinal axonal tract (central-dorsal column) was evaluated for the sMEA and compared to those required for the rigid tungsten electrode. The threshold current required for the sMEA was found to be significantly greater than that required for the rigid electrode $(153 \pm 109$ vs. $47 \pm 24 \mu \mathrm{A}, 500 \mu \mathrm{s}$ biphasic pulses; paired Student's $t$-test: $p=<0.01, n=16$ ). However, the surface area of the sMEA electrode was an order of magnitude greater than that of the rigid tungsten microelectrode $\left(7,854 \mu \mathrm{m}^{2}\right.$ vs. maximum of $400 \mu \mathrm{m}^{2}$, assuming total electrode tip contact with the cord surface). As a result, the charge density required by the sMEA to elicit a minimum CAP $\left(972 \pm 696 \mu \mathrm{C} / \mathrm{cm}^{2}\right)$ was significantly less than that required for the rigid tungsten microelectrode $\left(5,910 \pm 3039 \mu \mathrm{C} / \mathrm{cm}^{2}\right.$; paired Student's $t$-test: $p=<0.01$ ). 


\section{SPATIAL STIMULUS RESOLUTION}

The spatial resolution of single-site sMEA stimulation was measured by evoking CAPs on surface spinal tracts and measuring the progressive bilateral reductions in CAP amplitude with orthogonal (lateral) distance from the site of maximal activation (Figure 2). For the 13 spinal cords tested, the evoked CAPs were recorded at orthogonally incremented locations from the site of maximal activation, approximately eight spinal segments caudal to the stimulation site. The sMEA and rigid tungsten electrodes were used to stimulate the cord surface at incrementing multiples of threshold (T-2T, in $0.2 \mathrm{~T}$ increments).

Compound action potential magnitude die-off was plotted as a function of lateral distance from site of maximal spinal tract activation in order to compare the stimulus resolution properties of both electrode types (Figure 3A). Paired $t$-tests failed to reveal significant differences in the sMEA's vs. rigid microelectrode's evoked CAPs' stimulus resolution. For both array and rigid electrode, increasing the stimulus amplitude increased the magnitude of CAP responses in a graded manner. These gradations appeared to be more evenly spaced in the case of rigid microelectrode stimulation, which may indicate a greater consistency in their electrode-to-axon distance due to rigid microelectrode flattening of the interfaced cord.

To determine overall resolution of lateral axonal tract activation, the CAP responses evoked by sMEA and rigid tungsten electrode stimulation at $1-2 \mathrm{~T}$ ranges $(0.2 \mathrm{~T}$ increments) were magnitude-normalized such that all maximal responses were equal to 1 (Figure 3B). The magnitudes of evoked CAPs for the sMEA and the rigid electrode both decreased to below 50\% within approximately $100 \mu \mathrm{m}$ of either side of the site of maximal spinal tract activation.

\section{AXONAL THRESHOLD SELECTIVITY}

We further tested the sMEA's ability to activate spinal axons in a controlled manner by assaying recruitment of higher-threshold axons as a function of electrode proximity $(n=13)$. Slowerconducting (smaller diameter) axons are known to be recruited at incrementally higher thresholds than faster-conducting (larger diameter) axons (Hursh, 1939); in this way, axonal conductionvelocity selectivity can help characterize this technology's ability to stimulate white matter axons in inverse order of their axon diameter.

Minimum conduction velocities $(\mathrm{m} / \mathrm{s})$ for the evoked CAPs were calculated using the measured distance between stimulating and recording electrodes and the latency of the slowest evoked responses at offset (Figure 4A). Because of the reduced temperature's slowing effect on axonal conduction-velocity, the conduction velocities evoked by $\mathrm{T}$ and $2 \mathrm{~T}$ stimulation using our present in vitro setup were not directly comparable to ranges reported in vivo at body temperature for $A \beta$ fibers $(16-36 \mathrm{~m} / \mathrm{s})$,
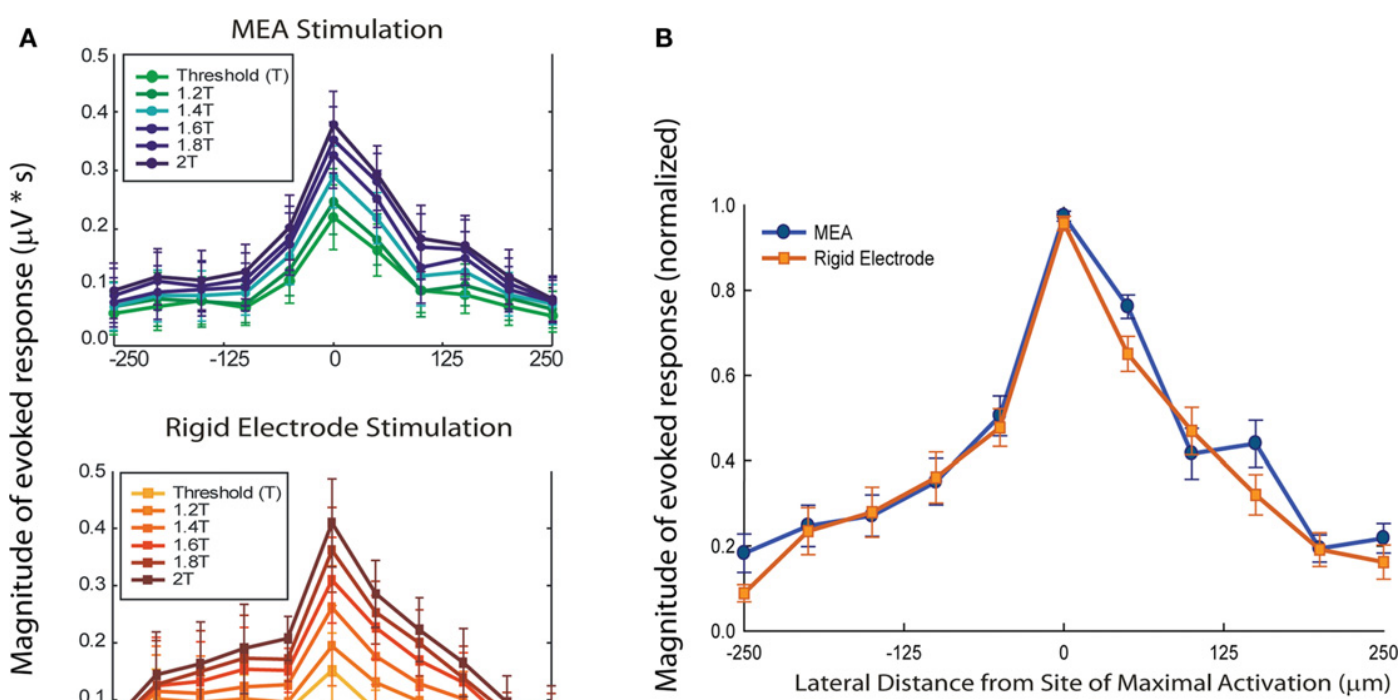

FIGURE 3 | Spatial stimulus selectivity of sMEA vs. tungsten microelectrode. The magnitude of evoked compound action potentials (CAPs; $\mu \mathrm{V} \times \mathrm{ms}$ ) on the central-dorsal column surface was measured and then plotted over lateral distance from site of maximal CAP response (i.e., the longitudinal location of the stimulating electrodes; $n=13$ ). CAP response magnitudes were calculated using the rectified, integrated, and baseline-subtracted responses for a fixed time window following the stimulus artifact. These values were then averaged over 10 trials for a given recording

site on the dorsal column. Standard error bars are shown. (A) Comparison of CAP magnitude over lateral distance from site of maximal activation with sMEA (top) and tungsten electrodes (bottom) at multiple stimulus intensities. (B) Magnitude-normalized comparison of lateral spread of axonal tract activation for sMEA and tungsten electrodes. The magnitudes of evoked CAPs for the MEA electrode pair and the rigid electrode each decreased to below $50 \%$ within approximately $100 \mu \mathrm{m}$ of either side of the site of maximal activation. 


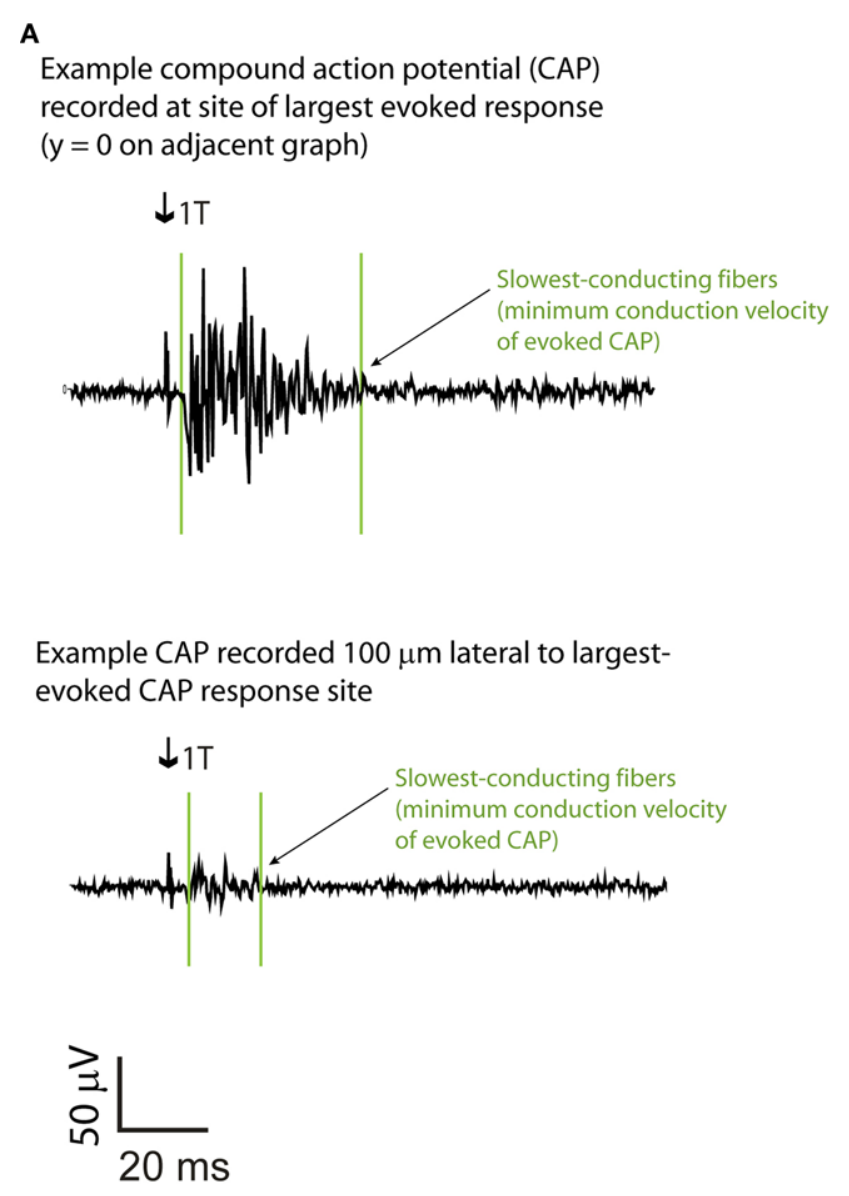

FIGURE 4 | Recruitment of slower-conducting axonal fibers: sMEA vs. tungsten microelectrode. Minimum conduction velocities were calculated for dorsal column CAPs evoked by single-site sMEA and tungsten microelectrode stimulation at threshold ( $T ; n=13$ ). (A) Example recordings of sMEA-evoked CAPs. The upper CAP was recorded on the longitudinal site of maximal recorded response (i.e., site of maximal activation) and the lower

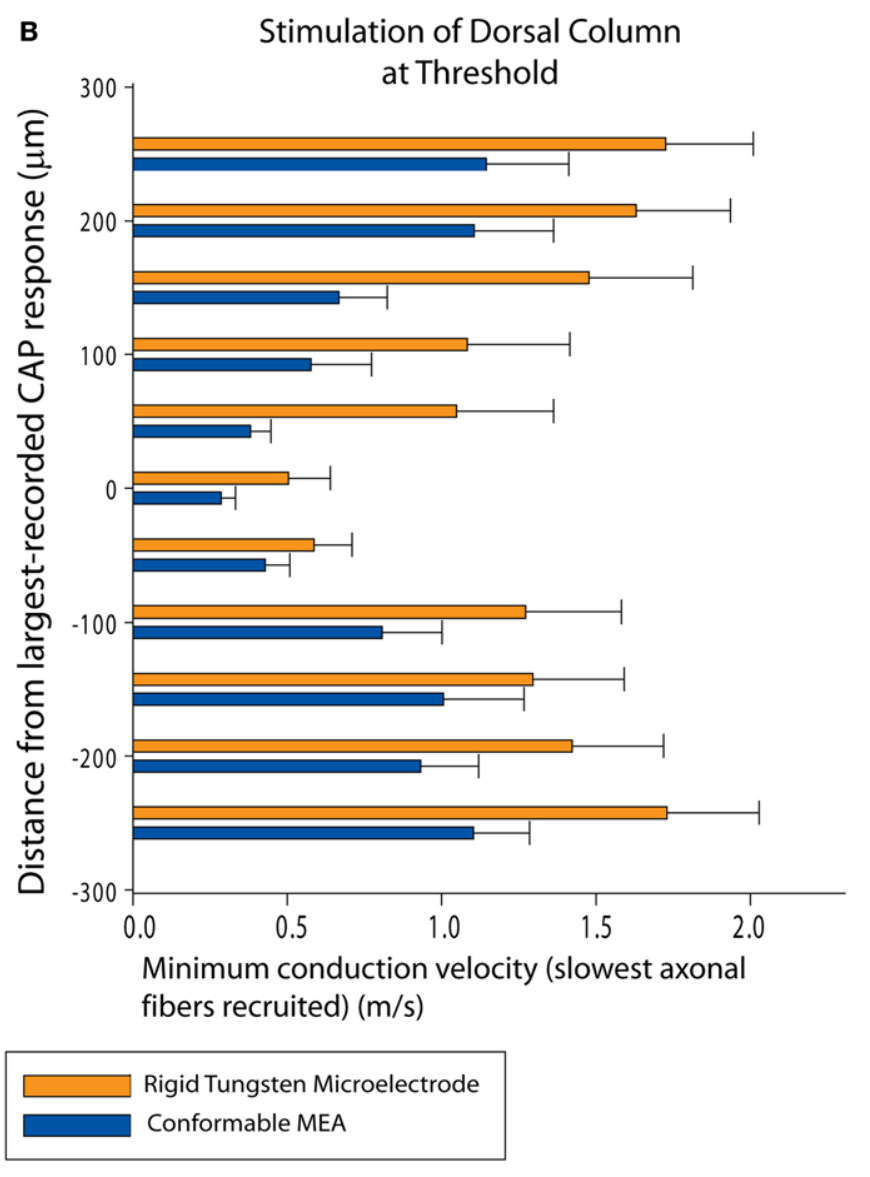

CAP was recorded on a white matter tract $100 \mu \mathrm{m}$ lateral to the site of maximal activation. Arrows indicate onset of stimulus artifact, and the vertical lines surrounding the responses indicate the onset and offset of the evoked CAP. (B) Minimum conduction velocities for the CAPs evoked by threshold current central-dorsal column stimulation, sMEA vs. tungsten microelectrode. nor for nociception-encoding $A \delta$ and C fibers (4-16 and 0.5-2 m/s, respectively, as measured in the rat; Suh et al., 1984; Chung and Coggeshall, 1987).

While studies using rat tail motor neuron axons have shown that lower temperatures slow axon conduction in a linear manner that would place axonal conduction-velocity ranges in our experiments within range of A $\beta$ fibers (Miyoshi and Goto, 1973), such extrapolations could not be applied definitively to the tested spinal tracts. This was due not just to the differences in temperature, but also the significant difference in the ratio of unmyelinatedto-myelinated fibers in the juvenile vs. adult rat dorsal column (Chung and Coggeshall, 1987).

Results comparing minimum conduction velocities of evoked CAPs demonstrated that both electrode types were capable of graded recruitment of slower-conducting fibers as a function of lateral proximity to the stimulus site (Figure 4B). Two-tailed, paired $t$-tests comparing these results showed that there was no statistically significant difference between the sMEA and tungsten electrode concerning ability to recruit slower axons as a function of electrode proximity.

At stimulus values of twice threshold current, the sMEA and tungsten electrode both evoked significantly slower axons (paired $t$-test, $p=0.040$ for sMEA and $p=0.070$ for tungsten electrode, minimum conduction velocities of $0.270 \pm 0.070$ and $0.254 \pm 0.070 \mathrm{~m} / \mathrm{s}$, respectively. These results demonstrate that sMEA and tungsten electrodes are similarly capable of modulating recruitment of slower-conducting fibers based on electrode position and stimulus amplitude.

\section{DUAL-SITE STIMULUS PRECISION}

For a subset of experiments ( $n=3$ cords), an additional pair of electrodes on the sMEA was used to stimulate a second site on the dorsal column surface. For each of the sites (approximately $400 \mu \mathrm{m}$ distance between electrode pairs), stimuli were applied independently at single-pulse threshold current levels (biphasic pulses, $500 \mu \mathrm{s}$ duration). As in the single-site 


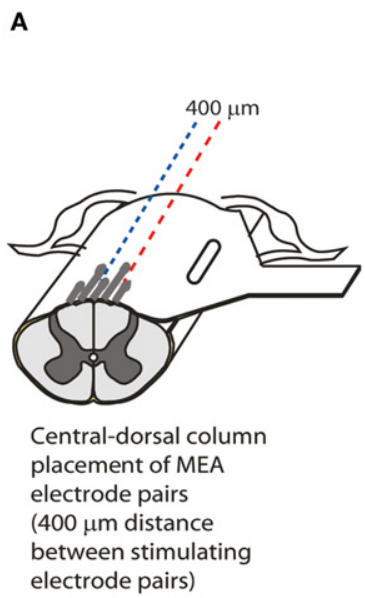

B

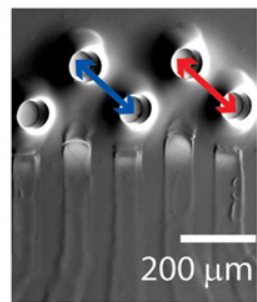

C

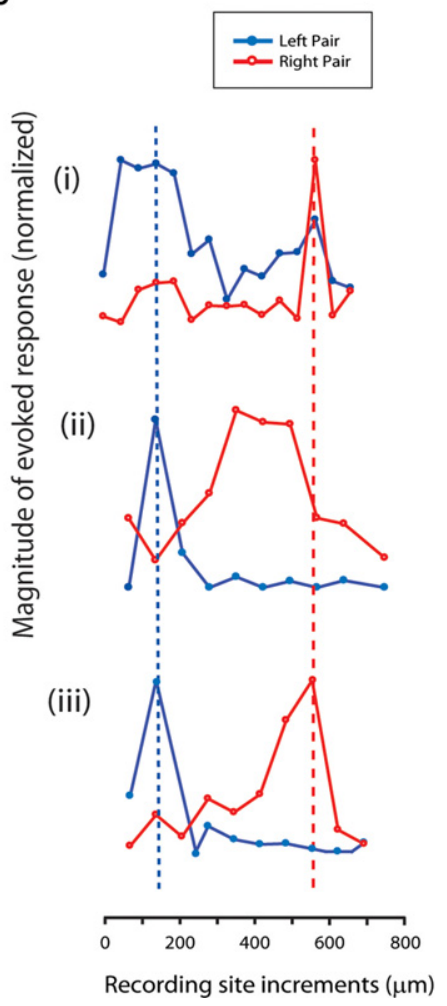

D

MEA Left Pair

Stimulation

(i)

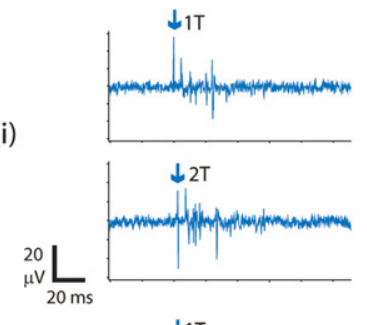

(ii)
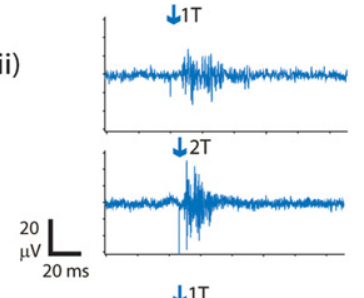

(iii)

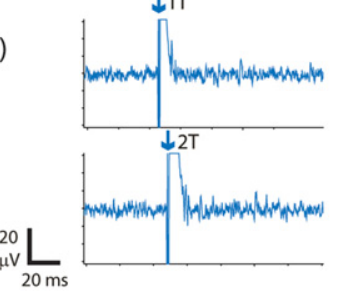

MEA Right Pair

Stimulation
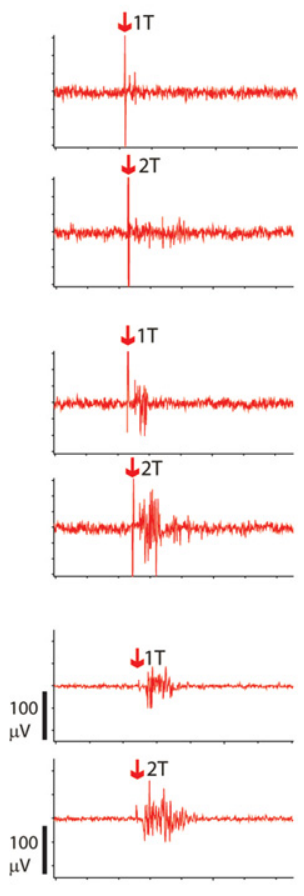

Time (ms)
FIGURE 5 | Adjacent pair sMEA stimulation of spinal tracts activates regionally distinct tracts. (A) The sMEA was placed on the central-dorsal column for bipolar stimulation of white matter tracts by adjacent pairs of electrodes ( $n=3$ cords). (B) Configuration for the adjacent sMEA electrode stimulation. A recording electrode was moved across the cord at a site orthogonal and caudal to the SMEA electrode placements and recorded CAP responses (similar setup to Figure 2A). (C) Recorded response magnitudes $(\mu \mathrm{A} \times \mathrm{ms})$ to evoked CAPs, as a function of distance from left-to-right across the spinal cord. Responses at a given site were averaged over 10 trials for a given recording site on the dorsal column (error bars not shown). For each independent spinal cord preparation [indicated by numerals (i-iii)], magnitudes of CAP responses were normalized such that the maximal recorded response on that cord equaled 1 (therefore, $Y$ axis $=1$ at highest points of (i-iii). Plots have been aligned to the peak response elicited by the left pair of electrodes. The dashed lines indicate a trend in relative location of CAP response magnitude peaks, which corresponds roughly to the distance between the two pairs of stimulating sMEA electrodes (two of the three cords demonstrated this trend). (D) Example CAPs evoked by sMEA pairs, at threshold current (1T) and twice threshold current (2T), measured at site of maximal activation (peaks in Figure 5C). Arrows indicate stimulus artifact. selectivity experiments, evoked CAPs were recorded at orthogonally incremented locations approximately eight segments caudal to the site of maximal activation. For all three cords on which the sMEA electrodes were placed on the central-dorsal column, distinct peaks in CAP response magnitude were found (Figure 5). The spacing of these peaks was approximately $400 \mu \mathrm{m}$ in two out of the three cords tested, and less than $400 \mu \mathrm{m}$ for the third cord.

These results showed that adjacent electrodes on the sMEA were capable of selectively recruiting distinct spinal tracts along the central-dorsal column of the in vitro spinal cord.

\section{MOTONEURON RECRUITMENT}

Experiments were conducted to determine if sMEA-based spinal tract surface stimulation was capable of activating motoneuron population responses associated with hindlimb flexor and extensor movement. Electrodes on the sMEA were placed on the lateral aspect of the T12 segment (DLF, LF, and VLF tracts). These regions are known to carry axons that subserve movement coordination (Davidoff, 1983; Jordan and Schmidt, 2002), and pulse-train stimulation of the in vitro VLF has been shown to elicit locomotor-like activity (Magnuson and Trinder, 1997; Antonino-Green et al., 2002). Adjacent electrodes on the sMEA were configured for bipolar stimulation of the three surface locations such that the distance between DLF and LF stimulation was approximately $400 \mu \mathrm{m}$ and the distance between LF and VLF stimulation was approximately $200 \mu \mathrm{m}$ (Figure 6A). Single-pulse current stimuli were delivered at minimum values required to evoke a visible ventral root response, which was measured at the second and fifth lumbar levels. In addition, CAPs evoked on the surface of the VLF and DLF were recorded at the sixth lumbar level to monitor axon tract recruitment. LF and VLF, but not DLF stimulation, elicited combined ventral root L2 and L5 responses (Figure $6 \mathrm{~B}, n=2$ ). Ventral root L5 responses were of greater magnitude and longer delay-to-onset when compared with ventral root L2 responses.

To further determine whether surface stimulation of the spinal cord using sMEA electrodes was capable of accessing hindlimb flexor and extensor related motoneuron populations, the sMEA was used to stimulate the T12 VLF using a train of pulses (Figure 6C, $n=1$ ). A pair of sMEA electrodes (bipolar current stimulation configuration) was placed on the VLF at thoracic level 
A

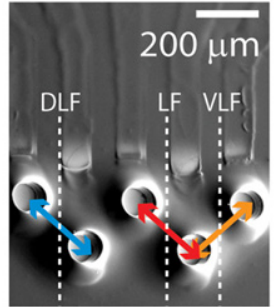

B

(i)

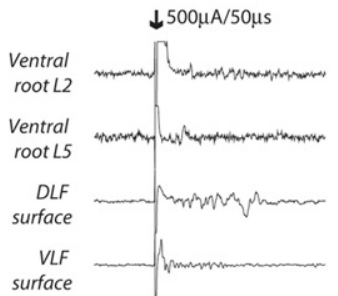

(ii)

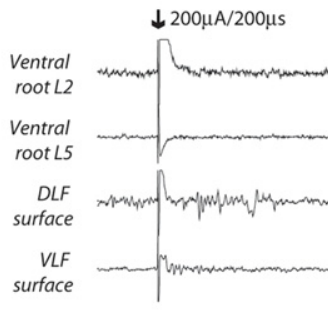

MEA Stimulation: Dorsolateral Funiculus (DLF)
MEA Stimulation: Lateral Funiculus (LF)

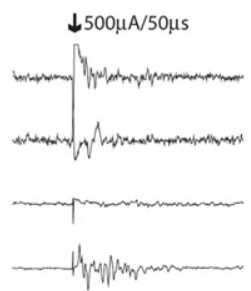

MEA Stimulation: Ventrolateral Funiculus (VLF)
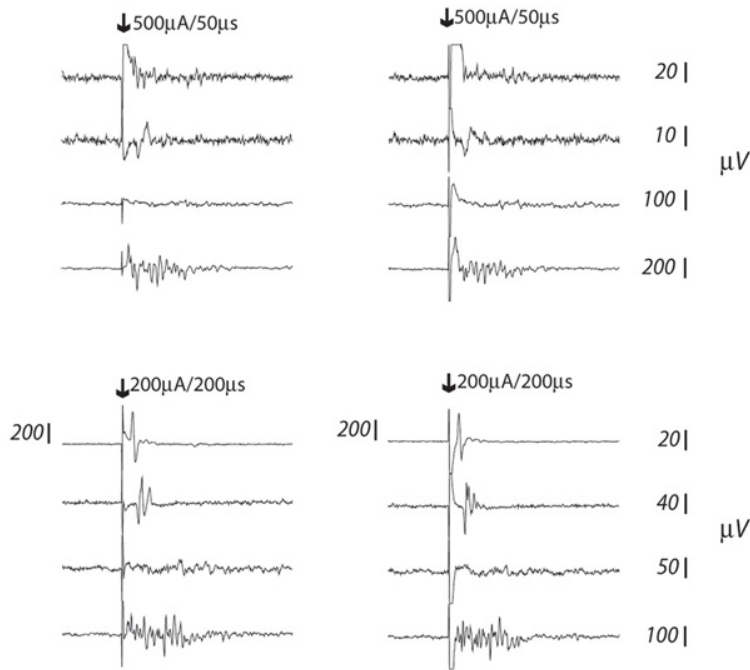

$20 \mathrm{~ms}$

C MEA Stimulation of VLF Using a Pulse Train

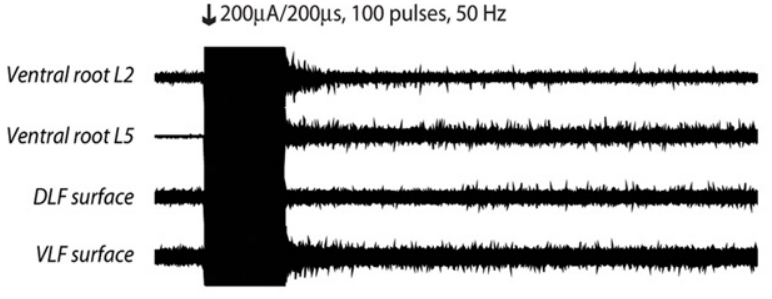

$200 \mathrm{~ms}$

FIGURE 6 | Hindlimb flexor- and extensor related responses to sMEA electrode stimulation at three distinct surface sites. Adjacent SMEA electrode pairs were used to deliver separate stimuli to the T12 DLF, LF, and VLF ( $n=2$, eight stimulus trials per site, representative traces from one trial per site shown). (A) Electrodes were configured for bipolar stimulation of the three surface locations. (B) Response recordings were made at ventral roots

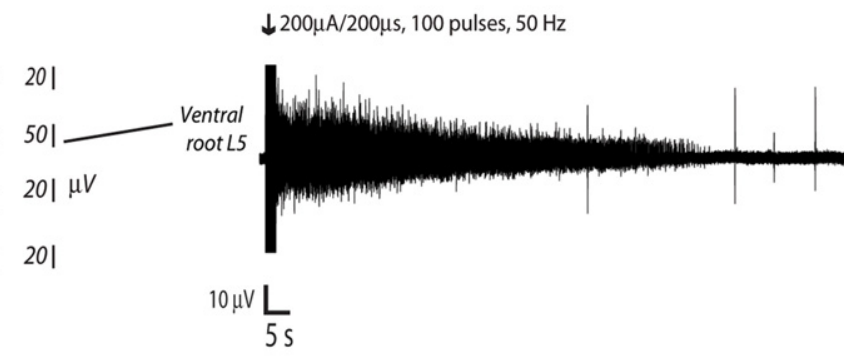

L2 and L5 (as well as at at the DLF and VLF L6 surfaces, in order to determine the ability of the sMEA to activate distinct motor patterns. Numerals (i,ii) indicate separate spinal cord preparations. (C) A sMEA electrode pair was placed on the VLF at thoracic level 12 (T12) and responses were recorded at ventral root L2, ventral root L5, the L6 DLF surface, and the I6 VLF surface. At right, a longer-duration tracing shows ventral root L5's prolonged activity.
12 (T12) and a train of 100 pulses $(200 \mu \mathrm{A} / 200 \mu \mathrm{s})$ was delivered at a frequency of $50 \mathrm{~Hz}$. There was prolonged activity in the VLF as well as ventral roots L2 and L5; this prolonged activity lasted over 1 min in ventral root L5 (Figure 6C).

A total of two sMEAs were used for the $20+$ in vitro, abovementioned experiments. These sMEAs were found to be mechanically durable and re-usable without signs of delamination or decomposition. For the several months over which these sMEAs were repeatedly manipulated, they were constantly soaking in either a CSF or deionized water (in between experiments). The temporal consistency of the sMEAs' electrical properties was not formally tested; however, the required currents for evoking CAPs on in vitro cords displayed consistent ranges across months of experiments: for sMEA \#1, the beginning and ending experiments required 300 and $200 \mu \mathrm{A}$ (total range: $200-300 \mu \mathrm{A}$ with a 20 $\mu \mathrm{A}$ outlier); for sMEA \#2, the beginning and ending experiments required 50 and $150 \mu \mathrm{A}$ (total range: $50-250 \mu \mathrm{A}$ ). A single, chargebalanced pulse of $500 \mu \mathrm{s}$ duration was used to find each threshold current value.

\section{DISCUSSION}

The sMEA's ability to precisely stimulate spinal surface axons was evaluated by comparing its activation profile to that of rigid (tungsten) bipolar microelectrodes pressed directly onto the cord. The regional selectivity of the sMEA was similar to that of the rigid electrode; however, the rigid electrode displayed a slightly more even gradation. While the reasons for this difference are undetermined, they may be related to the way in which the rigid microelectrode 
was pressed onto its interfaced cord surface, which visibly flattened the surrounding cord surface.

When compared to rigid microelectrodes, the sMEA demonstrated a lower minimum charge density required to activate dorsal column surface tracts. This confers a considerable advantage over the rigid tungsten microelectrode in terms of safe and effective stimulation of the cord surface (Cogan, 2008). However, the sMEA's threshold charge density is still higher than the threshold charge densities required for neural prosthetic surface stimulation of the human retina, optic nerve, cortex, auditory brainstem, and sciatic nerve (summarized in Cogan, 2008). This may be due to a greater distance (and/or greater aCSF shunting) between our sMEA electrode and the tissue, as compared the aforementioned studies. The potential for the charge density provided by the sMEA to incur damage to its interfaced neural tissue remains largely undetermined, and will require further investigation as sMEA-interfacing studies continue.

We have demonstrated that the strength of sMEA-evoked CAP response decays over lateral (orthogonal) distance in a manner similar to that evoked by the bipolar tungsten microelectrode, and that threshold stimulation of the dorsal column using adjacent sMEA electrodes was capable of non-overlapping recruitment of parallel tracts along the central-dorsal column.

The magnitudes of evoked CAPs for the sMEA electrode pair and the rigid electrode both decreased to below 50\% within approximately $100 \mu \mathrm{m}$ of either side of the site of maximal activation. An MEA electrode stimulus resolution of $200 \mu \mathrm{m}$ is roughly equivalent to anywhere from 27 to 270 adult rat dorsal column axon widths, assuming that at least $2 / 3$ of the axons in the dorsal column are myelinated $A \alpha, A \beta$, or propriospinal fibers with diameters of $1-10 \mu \mathrm{m}$, and that the remaining $1 / 3$ of axons are $\mathrm{A} \delta, \mathrm{C}$, or unmyelinated propriospinal fibers with diameters of 0.2-1 $\mu \mathrm{m}$ (Russell, 1980; Chung and Coggeshall, 1983; Patterson et al., 1989).

Our conclusion that the observed CAP decays were the result of a focused current delivery relies on the assumption that the activated dorsal column axons propagate their signals caudally with negligible loss or (postsynaptic) addition of activity. This assumption is supported by the fact that the dorsal column (aside from the deepest white matter) contains mostly primary afferents and postsynaptic dorsal column tract cells, which can be activated both antidromically and orthodromically (Willis and Coggeshall, 2004). As the presented experiments did not incorporate pharmacologic block of synaptic transmission, the contribution of synaptically recruited spiking of postsynaptic dorsal column tract cells cannot be excluded. Nonetheless, such recruitment following a single stimulus is unlikely to produce a suprathreshold synaptic response in these neurons (Jankowska et al., 1979).

Another assumption made in interpreting the observed CAP decays is that gray matter deep to the dorsal column was not activated by threshold stimulation at the surface. This likely, as axons are activated at lower thresholds than their associated cell bodies (Gustafsson and Jankowska, 1976; Gaunt et al., 2006) and only low threshold stimuli were used to recruit only the largest and most easily recruited axons.

A comparison of minimum CAP conduction velocities evoked by the sMEA and tungsten microelectrode stimulation

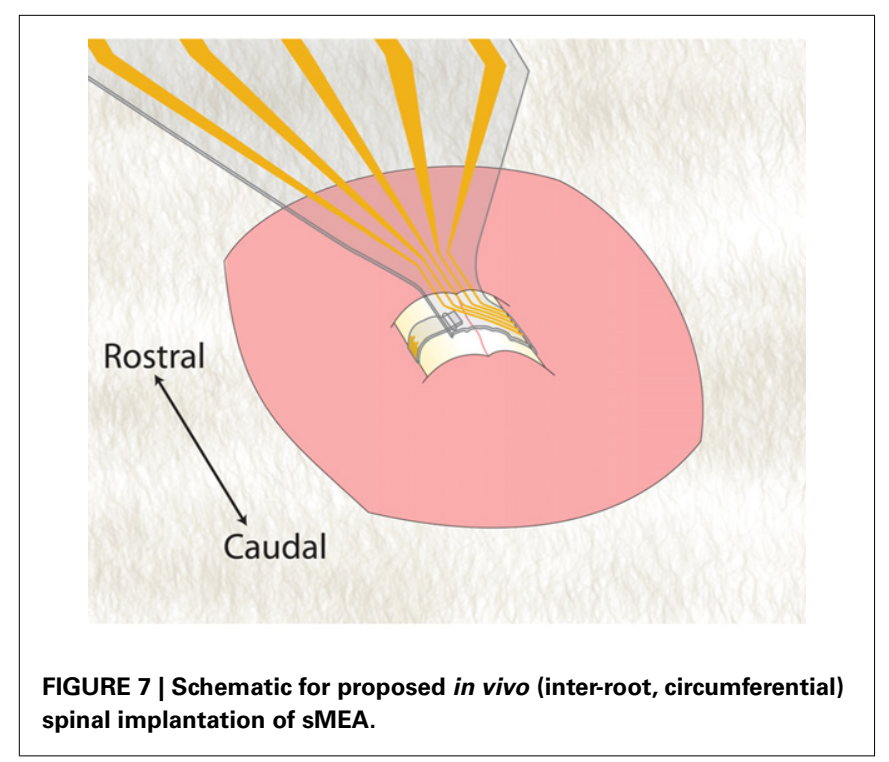

demonstrated a progressively reduced recruitment of higherthreshold (slower-conducting, smaller diameter) fibers as a function of lateral distance to the stimulating electrode site. This suggests that both the sMEA and rigid tungsten electrodes are in adequate proximity to the cord surface to recruit axons in a manner dependent primarily on axonal activation properties. A significant limitation to our analysis of recruited axonal tracts was loss of faster components of the evoked responses in stimulus artifact. In future studies, stimulus artifact elimination technologies (Blum et al., 2007) can be used to circumvent this limitation and also enable closer-proximity response recordings.

The sMEA was used to stimulate the lower-thoracic (T12) dorsolateral, lateral, and ventrolateral funiculi, which are regions that have been shown to carry axons that subserve movement coordination (Chung and Coggeshall, 1983; Jordan and Schmidt, 2002). Threshold pulse stimulation of the LF and VLF, but not the DLF, was capable of eliciting combined ventral root L2 and L5 responses. Pulse-train stimulation of the T12 VLF evoked transient response bursts at ventral root L2 and the VLF surface, and produced longlasting excitability at ventral roots L2, L5, and surface DLF and VLF. It remains undetermined how much of this post-stimulus excitability was noise- and/or damage-related, and how much correlates with meaningful motor activity.

There are fundamental limitations to the correlation of evoked ventral root potentials recorded from in vitro, hemisected spinal cords to coordinated motor output. While the in vitro experiments performed here were appropriate for initial assessment of our sMEA's capabilities, a more intact preparation is required to determine whether sMEA stimulation of the spinal cord surface is capable of activating motor activity.

As with any device designed for implantation, biocompatibility characterization of the sMEA is an essential parallel step for in vivo development of neural prosthetics (Green et al., 2010; McCreery et al., 2004). In addition, further experiments must be performed to evaluate the sMEA's potential for in vivo spinal cord mechanical damage. 
One proposed sMEA configuration for these initial in vivo implantation experiments is illustrated in Figure 7. Using a dorsal laminectomy approach, the sMEA could be wrapped around the circumference of the cord segment in between root pairs. This approach would test the sMEA's potential ability to access multiple tracts on the anterolateral surface, which is presently a speculated advantage of this technology. The damage incurred by initial implantation - as well as long-term implantation both with and without FES - could then be evaluated.

To support the proposed, next-step implantation experiments, interconnect technology has been developed for the sMEA that provides stable electro-mechanical interfacing with external stimulators (Guo and DeWeerth, 2009a). Stabilization of the sMEA and wiring can be accomplished using spinal processes as anchoring points.

\section{CONCLUSION}

We have constructed specialized, elastomer-substrate sMEA technology that enables close-proximity, multi-point electrical interfacing to the spinal cord surface. The stimulus precision of the elastomer-substrate sMEA, when compared to rigid (tungsten) bipolar electrodes pressed directly onto the spinal cord surface, was similar in both regional selectivity and gradation. This gradation was demonstrated both by incrementally increased current amplitudes as well as by relative (lateral) distance of the recruited axons from the stimulus site.

The regional selectivity of the sMEA was quantified by measuring the axonal activation magnitude as a function of lateral

\section{REFERENCES}

Antonino-Green, D. M., Cheng, J., and Magnuson, D. S. (2002). Neurons labeled from locomotor-related ventrolateral funiculus stimulus sites in the neonatal rat spinal cord. J. Comp. Neurol. 442, 226-238.

Armani, D., Liu, C., and Aluru, N. (1999). "Re-configurable fluid circuits by PDMS elastomer micromachining," in Micro Electro Mechanical Systems MEMS '99. Twelfth IEEE International Conference on, Orlando, FL.

Belanger, M. C., and Marois, Y. (2001). Hemocompatibility, biocompatibility, inflammatory and in vivo studies of primary reference materials low-density polyethylene and polydimethylsiloxane: a review. J. Biomed. Mater. Res. 58, 467-477.

Biran, R., Martin, D. C., and Tresco, P. A. (2005). Neuronal cell loss accompanies the brain tissue response to chronically implanted silicon microelectrode arrays. Exp. Neurol. 195, 115-126.

Blum, R. A. R., Ross, J. D., and Brown, E. A., and DeWeerth, S. P. (2007). An integrated system for simultaneous, multichannel neuronal stimulation and recording. IEEE Trans. Circuits Syst. I Regul. Pap. 54, 10.
Brown, X. Q., Ookawa, K., and Wong, J. Y. (2005). Evaluation of polydimethylsiloxane scaffolds with physiologically-relevant elastic moduli: interplay of substrate mechanics and surface chemistry effects on vascular smooth muscle cell response. Biomaterials 26, 3123-3129.

Chung, K., and Coggeshall, R. E. (1983). Propriospinal fibers in the rat. $J$. Comp. Neurol. 217, 47-53. (1987). Postnatal development of the rat dorsal funiculus. J. Neurosci. 7, 972-977.

Cogan, S. F. (2008). Neural stimulation and recording electrodes. Annu. Rev. Biomed. Eng. 10, 275-309.

Courtine, G., Gerasimenko, Y., van den Brand, R., Yew, A., Musienko, P., Zhong, H., Song, B., Ao, Y., Ichiyama, R. M., Lavrov, I., Roy, R. R., Sofroniew, M. V., and Edgerton, V. R. (2009). Transformation of nonfunctional spinal circuits into functional states after the loss of brain input. Nat. Neurosci. 12, 1333-1342.

Davidoff, R. A. (1983). Handbook of the Spinal Cord. New York: Marcel Dekker, Inc.

Gaunt, R. A., Prochazka, A., Mushahwar, V. K., Guevremont, L., and Ellaway, P. H. (2006). Intraspinal
Chung, K. S., and Coggeshall, R. E.

(orthogonal) distance of the axons to the stimulus site, when stimulated at threshold values. The magnitudes of evoked CAPs for the sMEA electrode pair and the rigid electrode both decreased to below $50 \%$ within approximately $100 \mu \mathrm{m}$ of either lateral (orthogonal) distance side of the site of maximal activation. When using the sMEA to stimulate central-dorsal column surface sites $200 \mathrm{~mm}$ apart, the sMEA recruited non-overlapping parallel tracts.

Compared to the tungsten electrode, the sMEA demonstrated a lower minimum charge density required to activate dorsal column surface tracts. While these results are preliminary, they serve as important starting points for demonstrating the relative utility of the sMEA for axonal stimulation protocols.

The potential for the sMEA to incur harm to its interfaced neural tissue - via charge density, mechanical shear/compression, or otherwise - remains largely undetermined, and will require further investigation. If in vivo testing proves that the implanted sMEA is capable of minimal-damage spinal tract stimulation, and if this in vivo stimulation provides similar precision to that of the presented in vitro studies, this sMEA might be a powerful enabling technology for multiple neuro-interfacing protocols.

\section{ACKNOWLEDGMENTS}

We thank Dr. Stefan Clemens for initial figure help and Edgar Brown and Michael Sawchuk for guidance. We thank Dr. Konrad Rykaczewski for SEM images of the tungsten rigid microelectrode. We thank John Crawley for assistance in in vivo MEA implantation studies. This work was supported by NIH R01 EB00786-01 and NSF IBN-03490.

microstimulation excites multisegmental sensory afferents at lower stimulus levels than local alphamotoneuron responses. J. Neurophysiol. 96, 2995-3005.

Gerasimenko, Y., Roy, R. R., and Edgerton, V. R. (2008). Epidural stimulation: comparison of the spinal circuits that generate and control locomotion in rats, cats and humans. Exp. Neurol. 209, 417-425.

Green, R. A., Ordonez, J. S., Schuettler, M., Poole-Warren, L. A., Lovell, N. H., and Suaning, G. J. (2010). Cytotoxicity of implantable microelectrode arrays produced by laser micromachining. Biomaterials 31 , 886-893.

Grill, W. M., Norman, S. E., and Bellamkonda, R. V. (2009). Implanted neural interfaces: biochallenges and engineered solutions. Annu. Rev. Biomed. Eng. 11, 1-24.

Guertin, P. A., and Steuer, I. (2009). Key central pattern generators of the spinal cord. J. Neurosci. Res. 87, 2399-2405.

Guo, L. D., and DeWeerth, S. P. (2009a). "Implementation of integratable PDMS-based conformable microelectrode arrays using a multilayer wiring interconnect technology," in 31st Annual International Conference of the IEEE Engineering in Medicine and Biology Society, Minneapolis, MN, 1619-1622.

Guo, L. D., and DeWeerth, S. P. (2009b). "PDMS-based conformable microelectrode arrays with selectable novel 3-D microelectrode geometries for surface stimulation and recording," in 31st Annual International Conference of the IEEE Engineering in Medicine and Biology Society, Minneapolis, MN, 1623-1626.

Guo, L., Meacham, K. W., Hochman, S., and DeWeerth, S. P. (2010). A PDMS-based conical-well microelectrode array for surface stimulation and recording of neural tissues. IEEE Trans. Biomed. Eng. 57, 2485-2494.

Guo, L., Williams, K. K., Giuly, R. J., and DeWeerth, S. P. (2007). "A PDMSbased elastic multi-electrode array for spinal cord surface stimulation and its electrode modification to enhance performance," in Materials Research Society 2007 Spring Meeting, San Francisco, CA.

Guo, L., and DeWeerth, S. P. (2010). An effective lift-off method for patterning high-density gold interconnects on an elastomeric substrate. Small 6, 2847-2852.

Gustafsson, B., and Jankowska, E. (1976). Direct and indirect activation of nerve cells by electrical pulses 
applied extracellularly. J. Physiol. 258, 33-61.

Guven, D., Weiland, J. D., Maghribi, M., Davidson, J. C., Mahadevappa, M., Roizenblatt, R., Qiu, G., Krulevitz, P., Wang, X., Labree, L., and Humayun, M. S. (2006). Implantation of an inactive epiretinal poly(dimethyl siloxane) electrode array in dogs. Exp. Eye Res. 82, 81-90.

Hochman, S. (2007). Primer: spinal cord. Curr. Biol. 17, R950-R955.

Hursh, J. B. (1939). Conduction velocity and diameter of nerve fibers. Am. J. Physiol. 127, 9.

Iwahara, T., Atsuta, Y., Garcia-Rill, E., and Skinner, R. D. (1991). Locomotion induced by spinal cord stimulation in the neonate rat in vitro. Somatosens. Mot. Res. 8, 281-287.

Jankowska, E., Rastad, J., and Zarzecki, P. (1979). Segmental and supraspinal input to cells of origin of nonprimary fibres in the feline dorsal columns. J. Physiol. 290, 185-200.

Jordan, L. M., and Schmidt, B. J. (2002). Propriospinal neurons involved in the control of locomotion: potential targets for repair strategies? Prog. Brain Res. 137, 125-139.

Kiehn, O., and Kjaerulff, O. (1996). Spatiotemporal characteristics of 5HT and dopamine-induced rhythmic hindlimb activity in the in vitro neonatal rat. J. Neurophysiol. 75, 1472-1482.

Leventhal, D. K., Cohen, M., and Durand, D. M. (2006). Chronic histological effects of the flat interface nerve electrode. J. Neural Eng. 3, 102-113.

Loeb, G. E., Peck, R. A., and Martyniuk, J. (1995). Toward the ultimate metal microelectrode. J. Neurosci. Methods 63, 175-183.

Loy, D. N., Magnuson, D. S., Zhang, Y. P., Onifer, S. M., Mills, M. D., Cao, Q. L., Darnall, J. B., Fajardo, L. C., Burke, D. A., and Whittemore, S. R. (2002). Functional redundancy of ventral spinal locomotor pathways. J. Neurosci. 22, 315-323.

Magnuson, D. S., and Trinder, T. C. (1997). Locomotor rhythm evoked by ventrolateral funiculus stimulation in the neonatal rat spinal cord in vitro. J. Neurophysiol. 77, 200-206.

Mazuchowski, E. L. T., and Thibault, L. E. (2003). "Biomechanical properties of the human spinal cord and pia mater," in 2003 Summer Bioengineering Conference, Sonesta Beach Resort in Key Biscayne, FL, 1205-1206.

McConnell, G. C., Rees, H. D., Levey, A. I., Gutekunst, C. A., Gross, R.
E., and Bellamkonda, R. V. (2009). Implanted neural electrodes cause chronic, local inflammation that is correlated with local neurodegeneration. J. Neural Eng. 6, 56003.

McCreery, D., Pikov, V., Lossinsky, A., Bullara, L., Agnew, W. (2004). Arrays for chronic functional microstimulation of the lumbosacral spinal cord. IEEE Trans. Neural Syst. Rehabil. Eng. 12, 195-207.

McDonnall, D., Clark, G. A., and Norman, R. A. (2004). Interleaved, multisite electrical stimulation of cat sciatic nerve produces fatigue-resistant, ripple-free motor responses. IEEE Trans. Neural Syst. Rehabil. Eng. 12, 208-215.

Meacham, K. W., Giuly, R. J., Guo, L., Hochman, S., and DeWeerth, S. P. (2008). A lithographicallypatterned, elastic multi-electrode array for surface stimulation of the spinal cord. Biomed. Microdevices $10,259-269$.

Merrill, D. R., Bikson, M., and Jefferys, J. G. (2005). Electrical stimulation of excitable tissue: design of efficacious and safe protocols. J. Neurosci. Methods 141, 171-198.

Miyoshi, T., and Goto, I. (1973). Serial in vivo determinations of nerve conduction velocity in rat tails. Physiological and pathological changes. Electroencephalogr. Clin. Neurophysiol. 35, 125-131.

Mushahwar, V. K., and Horch, K. W. (1997). Proposed specifications for a lumbar spinal cord electrode array for control of lower extremities in paraplegia. IEEE Trans. Rehabil. Eng. 5, 237-243.

National Institute of Neurological Disorders and Stroke. (2009). N. Amyotrophic Lateral Sclerosis Fact Sheet. Available at: http://www.ninds.nih. gov/disorders/amyotrophiclateralscl erosis/detail_amyotrophiclateralscle rosis.htm

Noga, B. R., Kriellaars, D. J., Brownstone, R. M., and Jordan, L. M. (2003). Mechanism for activation of locomotor centers in the spinal cord by stimulation of the mesencephalic locomotor region. J. Neurophysiol. 90, 1464-1478.

NSCISC. (2008). Spinal Cord Injury Facts \& Figures at a Glance 2008. Birmingham, AL: National Spinal Cord Injury Statistical Center.

Patterson, J. T., Head, P. A., McNeill, D. L, Chung, K., and Coggeshall, R. E. (1989). Ascending unmyelinated primary afferent fibers in the dorsal funiculus. J. Comp. Neurol. 290, 384-390.
Peckham, P. H., and Knutson, J. S. (2005). Functional electrical stimulation for neuromuscular applications. Annu. Rev. Biomed. Eng. 7, 327-360.

Peterson, S. L. McDonald, A., Gourley, P. L., and Sasaki, D. Y. (2005). Poly(dimethylsiloxane) thin films as biocompatible coatings for microfluidic devices: cell culture and flow studies with glial cells. J. Biomed. Mater. Res. A 72, 10-18.

Ranck, J. B. Jr. (1975). Which elements are excited in electrical stimulation of mammalian central nervous system: a review. Brain Res. 98, 417-440.

Rodgers, D. C. F., Fong, A. J., Lia, W., Ameri, H., Ahuja, A. K., Gutierrez, C., Lavrov, I., Zhong, H., Menon, P. R., Meng, E., Burdick, J. W. Roy, R. R., Edgerton, V. R., Weiland, J., Humayun, M. S., and Tai, Y. C. (2007). Flexible parylene-based multielectrode array technology for high-density neural stimulation and recording. Sensor. Actuator. B Chem. $132,449-460$

Rosamond, W., Flegal, K., Furie, K., Go, A., Greenlund, K., Haase, N. Hailpern, S. M., Ho, M., Howard, V., Kissela, B., Kittner, S., Lloyd-Jones, D., McDermott, M., Meigs, J., Moy, C., Nichol, G., O'Donnell, C., Roger, V., Sorlie, P., Steinberger, J., Thom, T., Wilson, M., Hong, Y., and for the American Heart Association Statistics Committee and Stroke Statistics Subcommittee. (2008). Heart disease and stroke statistics-2008 update: a report from the American Heart Association Statistics Committee and Stroke Statistics Subcommittee. Circulation 117, e25-e146.

Rousche, P. J., Pellinen, D. S., Pivin, D. P. Jr., Williams, J. C., Vetter, R. J., and Kipke, D. R. (2001). Flexible polyimide-based intracortical electrode arrays with bioactive capability. IEEE Trans. Biomed. Eng. 48, 361-371.

Russell, N. J. (1980). Axonal conduction velocity changes following muscle tenotomy or deafferentation during development in the rat. J. Physiol. $298,347-360$

Rutten, W. L. (2002). Selective electrical interfaces with the nervous system. Annu. Rev. Biomed. Eng. 4, 407-452.

Saigal, R., Renzi, C., and Mushahwar, V. K. (2004). Intraspinal microstimulation generates functional movements after spinal-cord injury. IEEE Trans. Neural Syst. Rehabil. Eng. 12, 430-440.

Suh, Y. S., Chung, K., and Coggeshall, R. E. (1984). A study of axonal diameters and areas in lumbosacral roots and nerves in the rat. J. Comp. Neurol. 222, 473-481.

Thompson, S. W., King,A. E., and Woolf, C. J. (1990). Activity-dependent changes in rat ventral horn neurons in vitro; summation of prolonged afferent evoked postsynaptic depolarizations produce a d2-amino-5-phosphonovaleric acid sensitive windup. Eur. J. Neurosci. 2, 638-649.

Todd, J., DeWeerth, S., and Hochman, S. (2009). "Sacral dorsal column stimulation induced locomotor-like activity is enhanced via turbocurarine and output-based positive feedback," in 39th Annual Meeting of the Society for Neuroscience, Chicago, IL.

Tresch, M. C., and Bizzi, E. (1999). Responses to spinal microstimulation in the chronically spinalized rat and their relationship to spinal systems activated by low threshold cutaneous stimulation. Exp. Brain Res. 129, 401-416.

Willis, W. D., Al-Chaer, E. D., Quast, M. J., and Westlund, K. N. (1999). A visceral pain pathway in the dorsal column of the spinal cord. Proc. Natl. Acad. Sci. U.S.A. 96, 7675-7679.

Willis, W. D., and Coggeshall, R. E. (2004). Sensory Mechanisms of the Spinal Cord. New York: Kiuwer Academic, Plenum Publishers.

Yang, X., Grosjean, C., and Tai, Y. C. (1998). "A low power MEMS silicone/parylene valve," in Solid-State Sensor and Actuator Workshop.

Conflict of Interest Statement: The authors declare that the research was conducted in the absence of any commercial or financial relationships that could be construed as a potential conflict of interest.

Received: 26 January 2011; accepted: 01 April 2011; published online: 21 April 2011.

Citation: Meacham KW, Guo L, DeWeerth SP and Hochman S (2011) Selective stimulation of the spinal cord surface using a stretchable microelectrode array. Front. Neuroeng. 4:5. doi: 10.3389/fneng.2011.00005

Copyright @ 2011 Meacham, Guo, DeWeerth and Hochman. This is an open-access article subject to a nonexclusive license between the authors and Frontiers Media SA, which permits use, distribution and reproduction in other forums, provided the original authors and source are credited and other Frontiers conditions are complied with. 